\title{
Releasing and structural/mechanical properties of nano-particle/ /Punica granatum (Pomegranate) in poly(lactic-co-glycolic) acid/fibrin as nano-composite scaffold
}

\author{
Gorji $\mathrm{M}^{1}$, Zargar $\mathrm{A}^{2}$, Setayeshmehr $\mathrm{M}^{2}$, Ghasemi $\mathrm{N}^{1}$, Soleimani $\mathrm{M}^{1}$, Kazemi $\mathrm{M}^{3}$, Hashemibeni $\mathrm{B}^{1}$ \\ Department of Anatomical Sciences and Molecular Biology, Faculty of Medicine, Isfahan University \\ of Medical Sciences, Isfahan, Iran. hashemibeni@med.mui.ac.ir
}

\begin{abstract}
The effect of poly(lactic-co-glycolic acid) (PLGA) on structure, degradation, drug release and mechanical properties of fibrin/pomegranate(F/POM)-based drug-eluting scaffolds have been studied comprehensively. METHODS AND MATERIAL: Nanoparticle-fibrin is prepared from thrombin and fibrinogen dissolved in $\mathrm{NaOH}$ and $\mathrm{HCl}$. Then pomegranate powder is added to it. Nanoparticles/pom are provided by freeze drying and freeze milling. The 3-D scaffold of poly(lactide-co-glycolic acid) (PLGA) was prepared via salt-leaching solvent/casting leaching method and impregnated with nanofibrin-pom. Structural and chemical component of the scaffolds were evaluated by transmission and scanning electron microscopy and furrier transmission infrared spectroscopy, respectively. Moreover, the scaffolds were characterized from the degradation rate and drug releasing rate points of view of human Adipose Derive Stem Cells (hADSCs). Cytotoxicity effects of the scaffold were evaluated on hADSCs via MTT assay.

RESULTS: The results showed that the size of nanoparticles was about $100 \mathrm{~nm}$. The scaffold had a slow degradation rate and it caused a sustained release pattern of pom. MTT assay indicated that nanoparticles had no cytotoxicity and fibrin-pom nanoparticles increased compressive strength of PLGA/scaffolds dramatically and also caused a proper compressive modulus.

CONCLUSIONS: By adding F/POM nanoparticle to PLGA and fabricating a three-dimensional nanocomposite scaffold (PLGA/F/POM nanoparticle), special physical and mechanical properties also suitable for drug release and cell behavior were achieved, which makes it suitable for cartilage tissue engineering applications (Tab. 1, Fig. 7, Ref. 53). Text in PDF www.elis.sk KEY WORDS: hybrid composites, drug delivery, carrier, nanoparticles, scaffold.
\end{abstract}

\section{Introduction}

Scaffolds providing physical and chemical kinds of support for tissue engineeringare used to mimic the function of natural ECM. The synthetic scaffolds represent proper mechanical properties, butthe absence of proper biological cues can be considered as their disadvantage $(1,2)$.

Recently, Endres et al showed that the 3D arrangement of human articular chondrocytes in human fibrin glue and resorbable polyglycolic acid (PGA) scaffolds is an ideal system for cartilage

${ }^{1}$ Department of Anatomical Sciences and Molecular Biology, Faculty of Medicine, Isfahan University of Medical Sciences, Isfahan, Iran, ${ }^{2}$ Biomaterials Nanotechnology and Tissue Engineering Group, Department of Advanced Medical Technology, Isfahan University of Medical Sciences, Isfahan, and ${ }^{3}$ Molecular Biology, Faculty of Medicine, Isfahan University of Medical Sciences, Isfahan, Iran

Address for correspondence: B. Hashemibeni. Department of Anatomical Sciences and Molecular Biology, Faculty of Medicine, Isfahan University of Medical Sciences, Isfahan, Iran.

Phone: +98.31.37929153

Acknowledgement: The authors acknowledge the support provided by the Isfahan University of Medical Sciences in association with this research. regeneration $(3,4)$. Previous studies have also confirmed that fibrin and PLGA could promote the homogeneous cell distribution (5). Our previous studies also indicated that fibrin was a proper cell carrier to seed cells within the polymeric scaffolds $(6,7)$.

Poly(lactic-co-glycolic acid) (PLGA) is a biocompatible and biodegradable scaffold functionalized for regenerative medicine $(8,9)$, demineralized bone particles $(10)$, and fibrin (11) can be considered for cartilage tissue engineering applications.

Natural polymers can mimic cell behaviors similar to those of the normal tissue $(8,12)$. Fibrin, known as protein hydrogels derived from fibrinogen, can be collected and isolated from the patient's autologous blood (13). Fibrin has been widely considered in medicine and material sciences applications such as drug delivery, cell transplantation (14), biological glue (15), wound repair and tissue engineering $(11,16)$ However, it has such advantages as weak mechanical properties and fast degradation. Hence, it cannot be suitable for tissue regeneration by itself $(10,15)$.

A hybrid scaffold was fabricated by embedding the fibrin hydrogel into the PLGA framework, which incorporated both advantages of better mechanical performance of PLGA and the biological performance of fibrin (17). 
The high cost, rapid degradation and easy-lost activity of the growth factors are known as the disadvantages (18). Therefore, such disadvantages of using GFs lead to the development of research interests in herbal medicine.

Pomegranate is a native fruit from Iran extended to the Himalayas in the Northern India. Some of its components are mucilage, glycosides, phenols, tannins, flavonoids, anthocyanin pigments and alkaloids (19). Recently, some explorations have demonstrated that the pomegranate juice may be effective against prostate cancer (20), osteoarthritis (21) and cardiovascular diseases (22).

The extent to which these new drug delivery systems have been tested varies from studies that only examine the basic biocompatibility, material characteristics and drug release kinetics to those that have evaluated the potential of drug delivery systems in vitro, as well as those that have been evaluated in vivo. These systems further differ based on whether they involve the delivery of a single drug, the simultaneous delivery of multiple drugs, the sequential delivery of multiple drugs, and the co-delivery of cells and single or multiple drugs (23).

The application of nanotechnology in medicine, such as nanomedicine, is offering numerous possibilities in TE and regenerative medicine (24). Nanoscale delivery vehicles can heighten the therapeutic efficacy and minimize the adversities associated with available drugs (1), enable the development of new types of therapeutics (2), and promote the re-investigation of pharmaceutically suboptimal but biologically active new molecular entities that were previously considered undevelopable $(3,25)$. Nanoparticles are engineered from organic and inorganic sources. Inorganic nanoparticles like those of gold, silver, titanium and iron are widely used for the fabrication of diagnostic and therapeutic tools (26). On the other hand, organic materials include natural biopolymers with many advantages such as high payload, biodegradability, biocompatibility and controlled release profile. Therefore, they can be one of the promising tools for the treatment of many diseases (27).

In this research, we developed a novel nanocomposite scaffold by herbal drug-release ability to improve the outcomes in tissue engineering. The scaffold was made from poly(lactic-co-glycolic acid) (PLGA) containing fibrin/pomegranate (F/POM) nano-particle to improve the physical and mechanical properties. The drug-release pattern and cell response of the scaffold were also investigated.

\section{Materials and methods}

\section{Preparation of the juice concentrates}

Juice extraction: Pomegranate (Punica granatum L.) fruits were washed and manually peeled; the juice was extracted manually. Large particles in the juice were removed by a mesh filter $(\mathrm{Nr}$ 9); the juice obtained was poured into polyethylene terephthalate bottles and stored at $-25{ }^{\circ} \mathrm{C}$ for less than one week until use for processing.

\section{Fibrin preparation}

Fresh frozen plasma (FFP) (16 ml) (Alzahra Hospital) and calcium gluconate $(10 \mathrm{ml})$ (Sinadarou) were mixed and incubated for $90 \mathrm{~min}$. Next, the mixture was centrifuged at 2,200 rpm for 10 min. The supernatant containing thrombin was accumulated and frozen. Fibrinogen was extracted from cryoprecipitate anti- hemophilic factor (AHF).

\section{Fibrin-pomegranate nanoparticles preparation (F/POM)}

The new method was performed to load the pomegranate powder physically. In brief, after placing the FFP pocket at $37^{\circ} \mathrm{C}(30$ minutes), the incubation of calcium gluconate $(10 \mathrm{ml})$ and FFP $(16 \mathrm{ml})$ was done for $90 \mathrm{~min}$. For thrombin isolation, the mixture formed in the previous stage was centrifuged. Fibrin (500 mg) was dissolved in $10 \mathrm{ml}$ of $\mathrm{NaOH}(1 \mathrm{~N})$ and diluted $\mathrm{HCl}(1 \mathrm{~N})$ was added in a drop-wise manner. Then, fibrin nanoparticles (FNP) were prepared at $\mathrm{pH}$ 5.5. After that, $500 \mathrm{mg}$ of Pom was added physically and by freeze meal, we had F/POM. Nanoparticles were sterilized using the UV radiation prior to use.

\section{Characterization of F/POM}

The size of NFP was measured by Zeta sizer Nano S (Malvern, UK). Also, the Zeta potential of nanoparticles was evaluated, showing the stability of colloidal dispersions (28). Fourier Transformation Infrared (FTIR) Spectrometry, JASCO V5300 FTIR (Tokyo, Japan), was also used to evaluate the chemical bonding, as well as the nanocomposite-containing materials.

The size and morphology of F/POM were shown by (TEM) (Philips CM200). For the TEM analysis, a drop of F/POM was placed on carbon-coated copper grid and dried under the infrared lamp'.

A scanning electron microscope (SEM) (Hitachi S-3400N) was used to analyze the internal pore morphology of the scaffolds. The samples were fractured and coated with gold with a sputtering method; then, their cross-section section was considered by SEM.

\section{Fabrication and characterization of the hybrid scaffold}

3-D PLGA (48/52wt \% poly (lactide)/poly(glycolide) scaffold was arranged using methylene chloride as previously described (5). Briefly, polymer/solvent solution ( $7.5 \% \mathrm{wt} / \mathrm{v}$ concentration of PLGA in methylene chloride) was prepared. fibrin/pom nanoparticles $(2.5 \% \mathrm{wt} / \mathrm{wt})$ were mixed with the polymeric solution cast in a mold $(10 * 5)$ and filled with $\mathrm{NaCl}$ (with identical size) as the porogen particles. Then, the scaffolds were dried and immersed in de-ionized water during 3 cycles to produce a highly porous structure. The fabricated scaffolds were sterilized using the UV radiation.

\section{Compressive strengths and modulus}

In order to assess the effect of the PLGA/F/POM compositions on the mechanical properties and stiffness, the pure PLGA, PLGA/F and PLGA/ F/POM samples were tested. The scaffolds were evaluated through (Instron 8874, Instron, USA and ASTM D1621-16 and ISO 844:2014 standards (five replicates)).

\section{Contact angle measurement}

The wettability of PLGA, PLGA/F and PLGA/F/POM scaffolds was determined using a water-contact angle measuring system (VCA Optima, AST Product, Inc). 


\section{Degradation rate}

The static immersion test was performed on pure PLGA, PLGA/F and PLGA/F/POM samples, where each of the 5 specimens $(10 \times 10 \times 5 \mathrm{~mm}$ in dimension $)$ was immersed in $14 \mathrm{~mL}$ PBS solution within a $15-\mathrm{mL}$ glass beaker. The assessment was done by this formula where $M_{1}$ is the primary weight and $M_{2}$ is final dry weight.

$$
\% \text { weight loss }=\frac{M_{1}-M_{2}}{M_{1}} \quad 100 \%
$$

\section{Drug release study}

PLGA/F/POM samples $\left(10 \times 10 \times 5 \mathrm{~mm}^{3}\right.$ in dimension $)$ were immersed in the PBS $\left(2.89 \mathrm{~g} / \mathrm{L} \mathrm{Na}_{2} \mathrm{HPO}_{3}, 8.1 \mathrm{~g} / \mathrm{L} \mathrm{NaCl}, 0.2 \mathrm{~g} / \mathrm{L}\right.$ $\mathrm{KCl}, 0.2 \mathrm{~g} / \mathrm{L} \mathrm{KH} 2 \mathrm{PO} 3)$ solution with $\mathrm{pH}$ of 7.4 in a water bath $[39,40]$. At a fixed interval, $1 \mathrm{~mL}$ aliquot of the solution was withdrawn to measure the released $\mathrm{F} / \mathrm{Pom}$ at a $365 \mathrm{~nm}$ wavelength. The technique is based on the daily cumulative releases of the F/POM.

\section{Cytotoxicity evaluation}

The cytotoxicity of scaffolds was assessed by MTT assay (29, 30). Moreover, the morphology of hADSCs on the surface of the PLGA/F and PLGA/F/POM scaffold was considered on the 7th day of cell culture using SEM.

\section{Statistical analysis}

All data are expressed as means \pm standard deviations (SD) $(\mathrm{n}=3-5)$ in this study. Statistical comparisons were performed using one-way ANOVA through Tukey's HSD (honest significant difference) test, wherever necessary.

\section{Results}

\section{Characterization of F/Pom}

DLS analysis revealed that the nanoparticles size was in the range of $120-150 \mathrm{~nm}$, as presented in Table 1 .

Figure 1 also shows the TEM image of nanoparticles in the PLGA matrix. Nanoparticles were visible due to the mass contrast between fibrin nanoparticles and the PLGA matrix, as shown by arrows. According to the TEM image, the size of nanoparticles was between 80 and $140 \mathrm{~nm}$. There was a good agreement in terms of the nanoparticles size between these two methods, showing that the nanoparticles were properly dispersed and no agglomeration had occurred (Fig. 2).

FTIR spectra of the nanofibrin/pomegranate nanoparticles-loaded PLGA are shown in Figure 3. The peak at 1,724 $\mathrm{cm}^{-1}$ showed C-O stretching, which was related to the stretching groups in the F/POM nanoparticles; the peaks at $1,146 \mathrm{~cm}^{-1}$ and $1,056.8$ $\mathrm{cm}^{-1}$ exhibited $\mathrm{OH}$, which was related to the deformation of primary and secondary alcohols, respectively (31).

Tab. 1. Size and zeta potential of fibrin and fibrin/pomegranate ( $F /$ POM) nanoparticles.

\begin{tabular}{lcc}
\hline Nanoparticle & Zeta; $\mathrm{P}$ & Size; $\mathrm{nm}$ \\
\hline Fibrin & 28 & 120 \\
F/POM & 21 & 136 \\
\hline
\end{tabular}

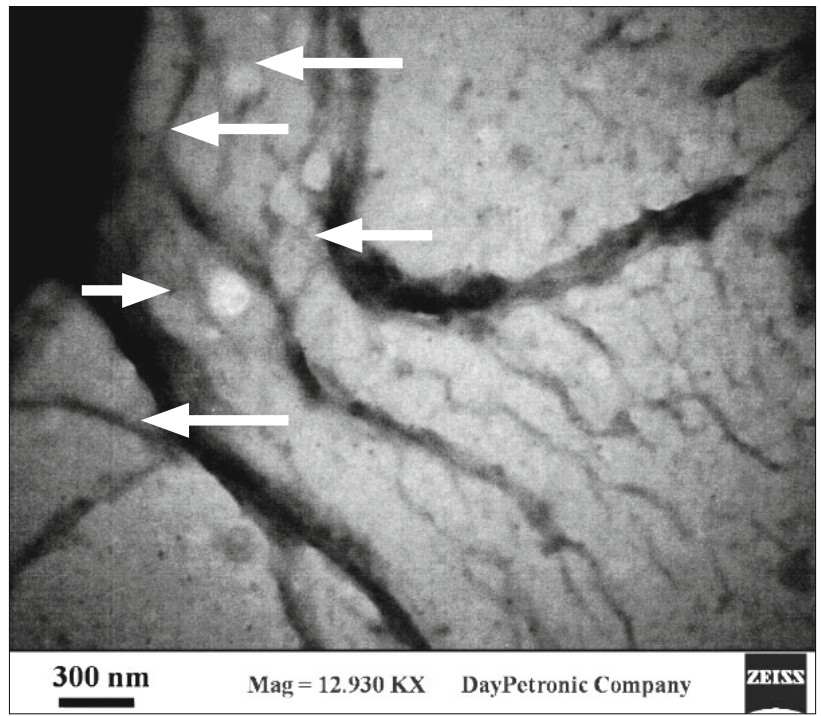

Fig.1. TEM Image of the F/POM nanoparticle in the PLGA matrix.

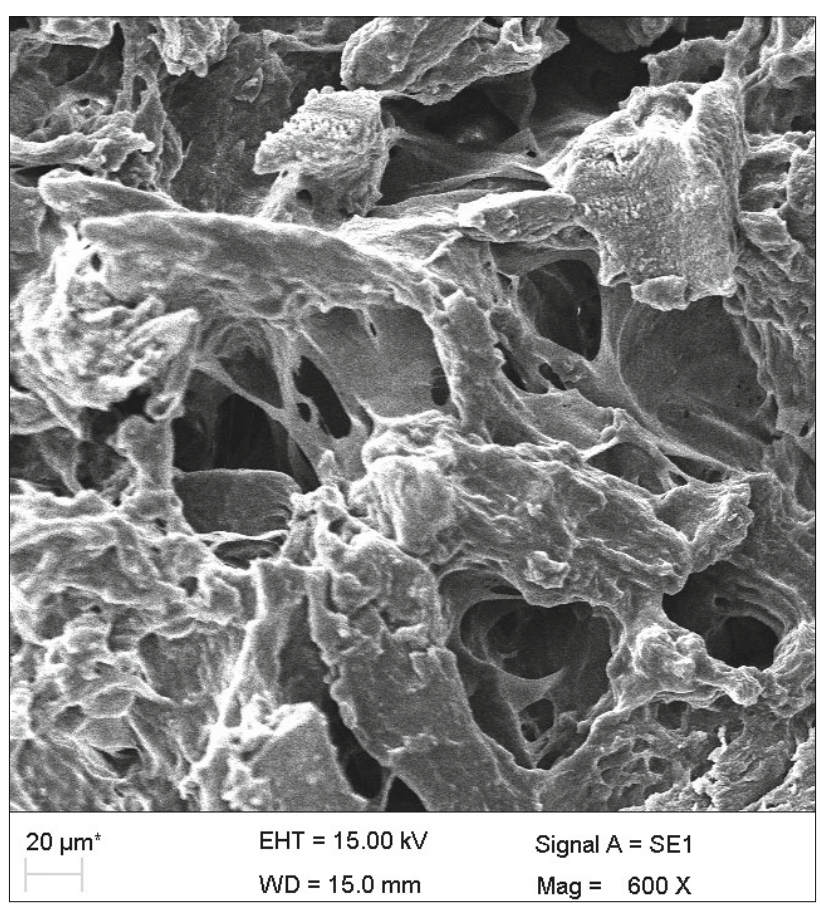

Fig. 2. SEM images of the PLGA/Fibrin/Pom.

FT-IR was used to characterize the PLGA/Fibrin hybrid scaffold. FT-IR spectra of the bulk PLGA and PLGA/Fibrin are shown in Figure 3. In the bulk PLGA, the main functional group peaks consisted of $-\mathrm{CH}, \mathrm{CH} 2, \mathrm{CH} 3\left(2800-2961 \mathrm{~cm}^{-1}\right)$, C-O (1045-1094 $\left.\mathrm{cm}^{-1}\right)$, ethyl -CH2 $\left(1420 \mathrm{~cm}^{-1}\right)$, OH $\left(3500 \mathrm{~cm}^{-1}\right)$ and carbonyl -CO $\left(1758 \mathrm{~cm}^{-1}\right)$. On the basis of the FT-IR spectra of PLGA/fibrin, the peaks at 1,657, 1,544 and 1,261 cm $\mathrm{cm}^{-1}$ corresponded to the characteristics of peaks of amide I, II, and III of fibrin; also, the FT-IR spectra showed the PLGA main functional group peaks (32). 

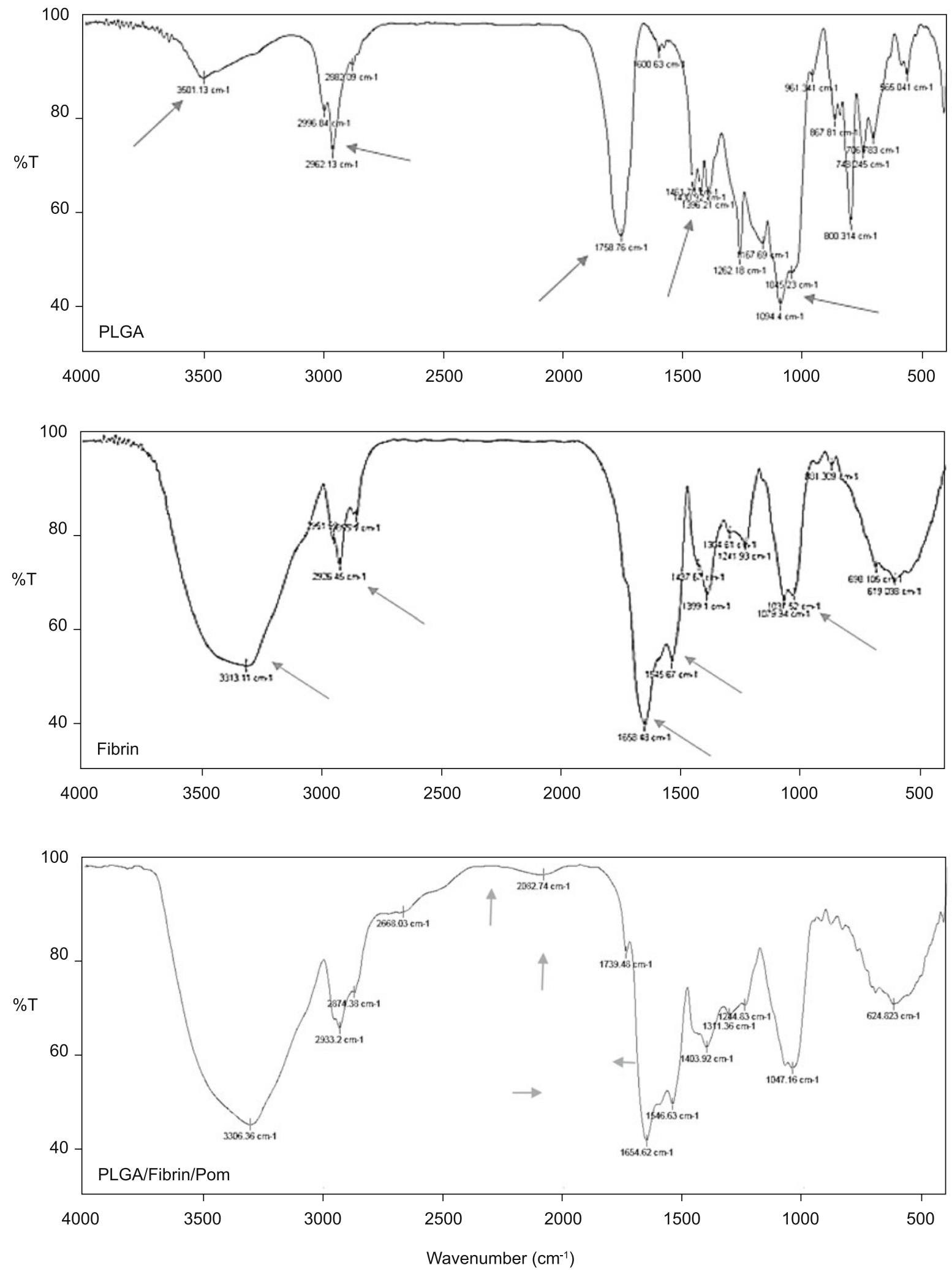

Fig. 3. FT IR spectra of the bulk PLGA, fibrin, PLGA/ fibrin/Pom. 

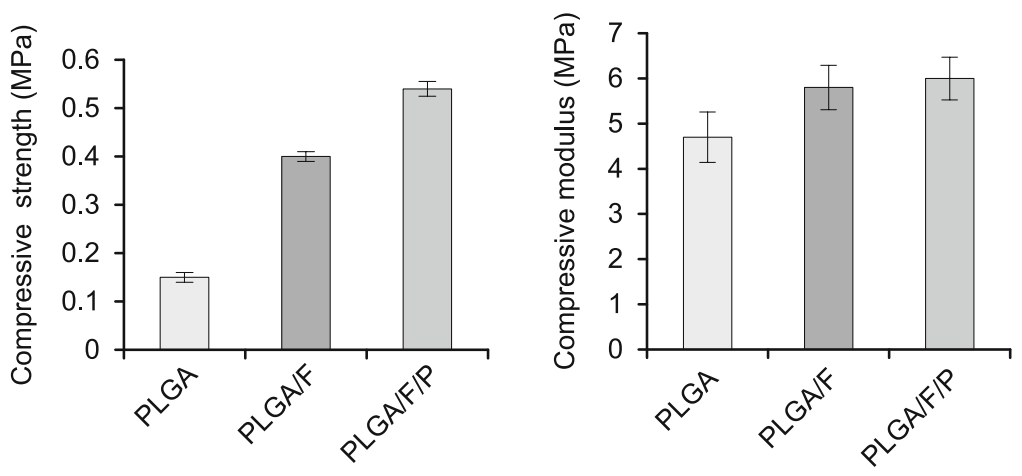

Fig. 4. Compressive modulus (Right) and Compressive strength (Left) of pure PLGA, PLGA/F and PLGA/F/POM samples.

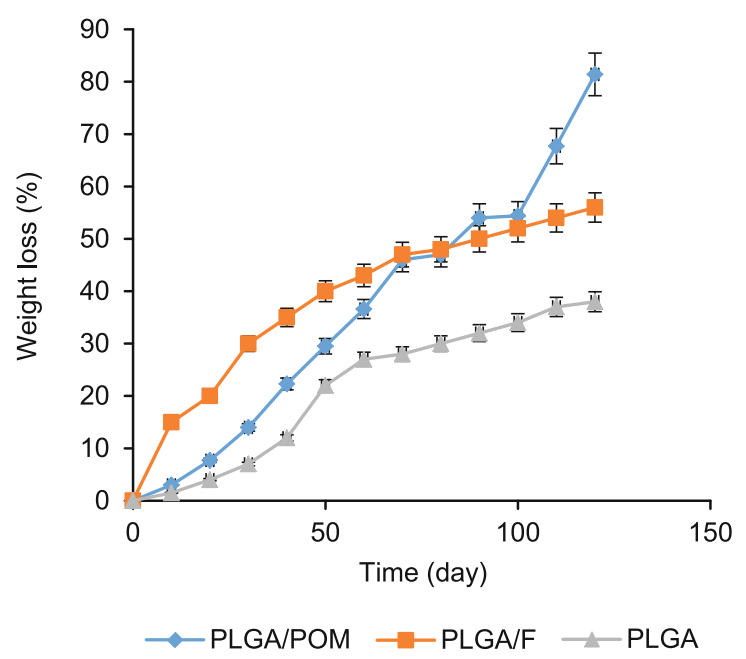

Fig. 5. Degradation rate according to weight loss percentage of PLGA, PLGA/F, PLGA/F/POM scaffold.

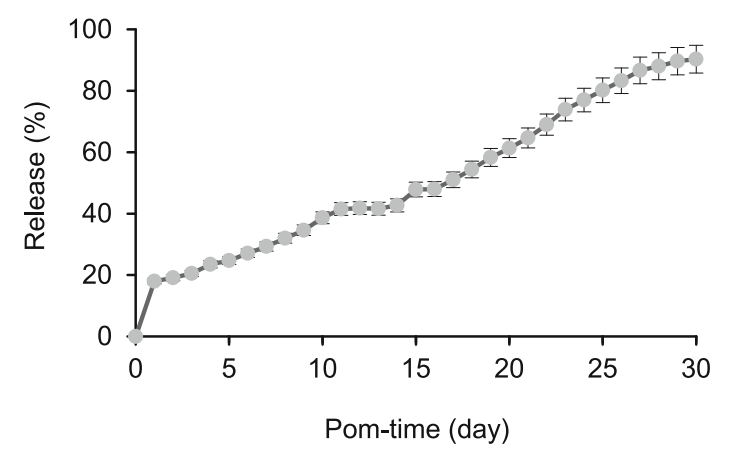

Fig. 6. Release of pomegranate extract from PLGA/F/POM scaffold.

The amide I' bands were at POM, and this band, as indicated in FTIR, was related to pomegranate at 1,634, 1,646, 1,659, 1,678, and $1690 \mathrm{~cm}^{-1}$ spectra, showing a peak at $1,634.38$. This proved the presence of pomegranate. There were peaks at 2,084.72,1,735; the peak in $3,300-3,500 \mathrm{~cm}^{-1}$ area, which could be attributed to the hydrogenic bonds (O-H) (33). four months.

\section{Mechanical properties}

Figures $4 \mathrm{a}$ and $4 \mathrm{~b}$ show the mechanical behavior of PLGA, PLGA/F and PLGA/F/ POM nanocomposite scaffolds under compressive force. Compressive modulus and compressive strength of the PLGA scaffold were $4.87 \mathrm{MPa}$ and $0.15 \mathrm{MPA}$, respectively. Adding fibrin to the PLGA caused an increase in the compressive modulus and compressive strength of the PLGA/F scaffold. The values reached to $6 \mathrm{MPa}$ and $0.4 \mathrm{MPa}$, respectively. By adding POM, the compressive modulus and compressive strength of PLGA/F/Pom were 6.3 MPa and $0.5 \mathrm{MPA}$, respectively.

The hydrogen bond formation between the $\mathrm{OH}$ groups of PGLA and amid groups of the fibrin, as well as between the acidic end of the PLGA and ester bond of fibrin, could be responsible for the impressive increase in the compressive strength of the PLGA/F composite, as compared to the PLGA scaffolds. By adding pomegranate, the hydrogen bond could be formed between the OH groups of PGLA and phenol compound of the pomegranate extract. Moreover, there was a significant interaction between hydrogen bonds and the center of the aromatic ring of pomegranate, thus increasing the mechanical strength of the PLGA/F/POM scaffolds, rather than that of other groups.

\section{Contact angle measurement}

The water contact angle on the PLGA, PLGA/F and PLGA/F/ POM surfaces was $83^{\circ}, 48^{\circ}$ and $42^{\circ}$, respectively. Hydrophilicity surface characteristics are related to surface roughness and pore diameter, as well as surface charge and surface functional groups.

By adding fibrin and F/POM nanoparticles to PLGA, hydrophilicity was increased. Although the incorporation of pomegranate into the scaffold caused more hydrophilicity because of its hydrophilic fractions, both of them could be suitable for the adherence of the stem cells.

\section{Degradation rate}

Figure 5 shows the degradation of the samples among the three groups as a function of the immersion time. The degradation of all specimens was increased progressively with time during the soaking period. The graph showed two degradation stages. In the first two months, the degradation rate was faster than in the 3 rd and 4th months. In semi-crystalline polyesters such as PLGA, the degradation from the major amorphous regions was initiated; then, hydrolytic attack was shifted toward the center of crystalline domains (34). However, due to the intrinsic hydrophobicity of PLGA, the weight loss was less than $50 \%$ after

As compared to the PLGA samples, PLGA/F and PLGA/F/ POM scaffolds showed more weight loss due to their higher hydrophilicity. It seems therefore, that the stronger hydrogen bonding (due to the existing aromatic ring) between F/POM nanoparticles and PLGA matrix was responsible for this phenomenon. 


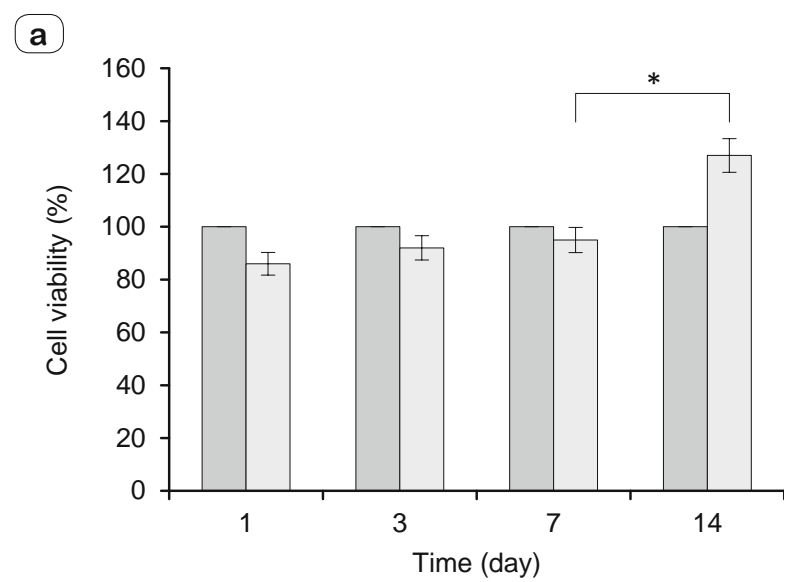

$\square \mathrm{PLGA} / \mathrm{F} \quad \square \mathrm{PLGA} / \mathrm{F} / \mathrm{POM}$
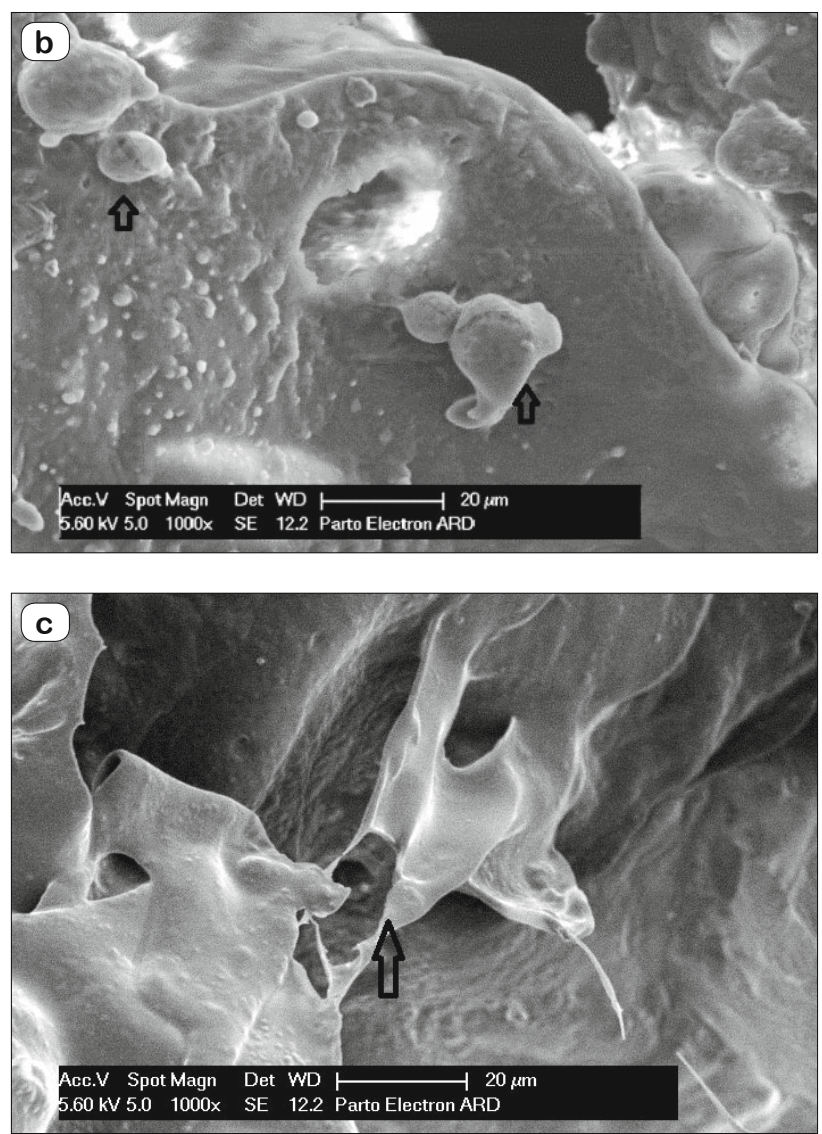

Fig. 7. (a) HADSCs viability on the PLGA/F and PLGA/Fibrin/POM scaffolds surface on days 1, 3, 7 and 14. (b) morphology of HADSCs after 3 days and (c) after7 days of cell culture on the PLGA/Fibrin/ POM scaffolds. (* means significant difference; $\mathbf{p}<0.05$ ).

\section{Drug release study}

The release patterns of pomegranate from the PLGA/F/POM nanocomposite scaffolds are presented in Figure 6. It can be concluded that a sustained release pattern has occurred. Approximately
$20 \%$ of POM was released in the first 24 hours and about $80 \%$ of the drug was released during the next 29 days. This phenomenon could be related to the secondary bonding created between the materials (35). In fact, the hydrogen bonding between the carboxylic groups of pomegranate and amide groups of fibrin delayed the release of the pomegranate extract from $\mathrm{F} / \mathrm{POM}$ nanoparticles. Moreover, hydrogen bonding between the hydroxyl group of PLGA and amide group of fibrin delayed the release of nanoparticles from the matrix. The mentioned effects could be enhanced due to the interaction between the hydrogen bonds and the center of aromatic ring of pomegranate.

The effect of the secondary bonds on the drug release pattern has been reported in previous researches. Sustained release of drugs is very important in the prolonged healing process such as tissue regeneration (36). In this manner, a drug carrier would be designed to release drug at a predetermined rate in order to maintain a constant drug concentration for a specific period of time with minimum side effects (37). The PLGA/F/POM scaffold could be suitable for this purpose along with the other physical and mechanical advantages.

\section{Cytotoxicity evaluation}

The results of cytotoxicity evaluation are presented in Figure $7 \mathrm{a}$. The cell viability percentage of HADSCs on the PLGA/F scaffold showed no significant difference with the control group (cell culture dish) on the 1st, 3rd, 7th and 14th days after cell culture. Therefore, cell viability was $100 \%$ at any preset time. In PLGA/F/POM, there was a decrease in the cell viability on the first day of cell culture. According to Figure 7a, on the 1st day, there was a high rate of pomegranate extract release in the cell culture media. It could decrease the acidity of the media and the cell environment, thus causing a delay in cell proliferation. Despite this, it could be observed that cell viability was increased in the next days, as there was no significant difference between the other groups on the $3 \mathrm{rd}$ and 7 th days of the cell culture. On the 14th day, a significant increase was observed in the cell viability percentage of the PLGA/F/POM scaffold. The increasing trend of cell viability from the first to 14th day indicated that the PLGA/F/POM scaffold did not have cellular toxicity against HADSCs.

Figures $7 \mathrm{~b}$ and $\mathrm{c}$ show the cell morphology of HADSCs on the PLGA/f/POM scaffolds on the 3rd and 7th days after cell culture. On the 3rd day, the cells were attached to the surface with a round morphology, which can be due to the effects of drug release. However, on the 7th day the cells were well inspired on the surface and attached to the surface via the cell filopodia. After 14 days, the cells covered the scaffold surface and formed a tissue layer (not presented). Various studies have reported that the surface hydrophilicity serves an important role in the cell morphology on non-toxic materials, while the 24-50 degree of contact angle is a suitable range for cell attachment and proliferation (36, 38). Cell morphology on the scaffold in the SEM image implies the cell compatibility of the scaffolds, and this was in agreement with the MTT results. 


\section{Discussion}

Hybrid scaffolds (natural/synthetic) can be considered as a forceful vehicle for tissue regeneration because they can integrate mechanical strength and biological cues by conjugating natural biomaterials with synthetic ones (37-38). In this research, a hybrid scaffold consisting of PLGA as the matrix and fibrin/pomegranate nanoparticles as the reinforcement was fabricated for cartilage tissue engineering applications. This combination significantly enhanced the mechanical properties of the scaffold and improved the hydrophilicity and consequently, the cell response. Moreover, this scaffold showed a sustained release of the pomegranate extract due to the hydrogen bonding created between components. Thus, it could be used as a novel drug carrier for the purpose of controlled drug release.

PLGA is a Food and Drug Administration-approved material with low immunogenicity, non-toxicity, and biodegradability. However, the lack of cell attachment sites, poor hydrophilicity, and low surface energy are the disadvantages of PLGA (39). By impregnating PLGA with natural polymers such as fibrin for scaffold fabrication, cell adhesion, proliferation and differentiation could be significantly improved (40-42).

Several previous studies have confirmed that the combination of fibrin with PLGA could promote a homogeneous cell distribution, cell seeding and chondrogenesis of the stem cells both in vitro and in vivo (43).

In the recent years, researchers have been studying the viability, proliferation (44), and differentiation of stem cells in different scaffolds with PLGA, but there is no detailed report on F/POM as the nanocomposite scaffold.

As an alternative to natural scaffolds, researchers have sought for a new delivery system that could provide the 3D microenvironment for tissue engineering to overcome the disadvantages mentioned above (45). Many synthetic polymers, each with different structural, biological and mechanical characteristics, have been used for this purpose. The most generally used synthetic polymers include PLLA, poly(glycolic acid) (PGA), PLGA, and poly(caprolactone) (PCL) as the porous structures (46). The size of macro-pores and the inter-pore connectivity of the $3 \mathrm{D}$ construction could affect the surface area and therefore, also the drug release kinetics. Additionally, the porosity and the inter-pore connectivity could affect the ability of cells to infiltrate and proliferate in and on the surface of the hybrid-scaffold (23). SEM in our study demonstrated that this hybrid scaffold could be suitable for proliferation and differentiation (40).

These synthetic polymers with copolymers are used as the vehicles for the controlled releases. Because of the degradation of the polymer, there is the release of the kinetics of the drug integrated into the matrix of the scaffold. The septum of the scaffold was impregnated with a drug and as the polymer was degraded, the drug was released. When the scaffold surfaces were coated with a polymer/drug layer, the release was controlled by the diffusion and degradation of the coating polymer (47).

The nanoparticles are broadly used in drug delivery, regenerative medicine, and tissue engineering researches. The particle size at the nanoscale is known as one of the special effects of biological and drug molecules for transfer to the target cells $(25,48,49)$.

In our study, F/POM nanoparticles were prepared and loaded in PLGA as a scaffold and a localized delivery system.

A considerable amount of research has been conducted on drug delivery by biodegradable polymers since their introduction as bioresorbable surgical devices about three decades ago. Amongst all biomaterials, the application of a biodegradable polymer, poly lactic-co-glycolic acid (PLGA), has shown an immense potential as a drug delivery carrier and as a scaffold for tissue engineering.

One of the main advantages of using such nano-sized particles as carrier systems was the efficacy of cellular uptake. Moreover, smaller particles possess larger surface-to-volume ratios, which thus results in a smart drug loading capacity, and consequently in slow rate of drug diffusion (50).

DLS measurements showed that the FNPs size was in the range of 120-150 nm, with the zeta potential value of $28 \mathrm{mV}$ in PBS ( $\mathrm{pH}$ 7.4). Such positive zeta potential nano-formulations could prevent particles from accumulation and help to repel each particle in the suspension, thus maintaining their stability for a long time. Moreover, there was a good agreement between the results of the TEM image and DLS, showing that the nanoparticles were not agglomerated (51).

Some researchers have reported different methods for FNP preparation, such as water-in-oil emulsification and cross-linking by the factor XIII or glutaraldehyde $(52,53)$. In our study, no cross-linking agents were used

\section{Conclusion}

In this research, the PLGA/F/POM hybrid was fabricated. This nanocomposite significantly improved the compressive strength and modulus of the scaffold due to the strong hydrogen bond created between the components. This secondary bond affected the rates of degradation rate and drug release of the scaffold. This means it caused a delay in the degradation rate and caused a sustained pattern in drug release. By adding the F/POM nanoparticles to the scaffold, there was improvement in hydrophilicity and consequently, cell morphology and cell proliferation. According to the research findings, the PLGA/F/POM nanocomposite scaffold could fulfill the needed physical and mechanical characteristics as a candidate scaffold for cartilage tissue engineering. Also, it could serve as a novel carrier for drug delivery in controlled release systems.

\section{References}

1. O'Keefe RJ, Mao J. Bone tissue engineering and regeneration: from discovery to the clinic - an overview. Tissue Engineer Part B: Rev 2011; 17 (6): 389-392.

2. Vinatier C, Mrugala D, Jorgensen C, Guicheux J, Noël D. Cartilage engineering: a crucial combination of cells, biomaterials and biofactors. Trends Biotechnol 2009; 27 (5): 307-314.

3. Endres M, Neumann K, Schröder S, Vetterlein S, Morawietz L, Ringe $\mathbf{J}$ et al. Human polymer-based cartilage grafts for the regeneration of articular cartilage defects. Tissue Cell 2007; 39 (5): 293-301. 
4. Garbacki N, Angenot L, Bassleer C, Damas J, Tits M. Effects of prodelphinidins isolated from Ribes nigrum on chondrocyte metabolism and COX activity. Naunyn-Schmiedeberg's Arch Pharmacol 2002; 365 (6): 434-441.

5. Zheng Y-x, Ringe J, Liang Z, Loch A, Chen L, Sittinger M. Osteogenic potential of human periosteum-derived progenitor cells in PLGA scaffold using allogeneic serum. J Zhejiang University SCIENCE B 2006; 7 (10): 817-824.

6. Bahrami M, Valiani A, Amirpour N, Rani MZR, Hashemibeni B. Cartilage tissue engineering via icariin and adipose-derived stem cells in fibrin scaffold. Adv Biom Res 2018; 7.

7. Valiani A, Izadi M, Bahramian H, Esfandiari E, Hashemibeni B. Comparison between the effect of kartogenin and TGF $\beta 3$ on chondrogenesis of human adipose-derived stem cells in fibrin scaffold. Bratisl Med J 2017; 118 (10): 591-597.

8. Khang G, Kim M, Cho S, Lee I, Rhee J, Lee H. Natural scaffolds biomaterials for tissue regeneration. Tissue Eng Regen Med 2004; 1 (1): 9.

9. Park GE, Pattison MA, Park K, Webster TJ. Accelerated chondrocyte functions on $\mathrm{NaOH}$-treated PLGA scaffolds. Biomaterials 2005; 26 (16): 3075-3082.

10. Jang J, Park K, Kim S, Park C, Kim M, Han C et al. Tissue engineered bone regeneration using DBP-loaded PLGA scaffold in rabbit model. Tissue Eng Regen Med 2005; 2 (1): 34.

11. Wang W, Li D, Wang M-c, Li Y-1, Gao C-y. A hybrid scaffold of poly (lactide-co-glycolide) sponge filled with fibrin gel for cartilage tissue engineering. Chinese J Polymer Scie 2011; 29 (2): 233-240.

12. Park SH, Park SR, Chung SI, Pai KS, Min BH. Tissue-engineered cartilage using fibrin/hyaluronan composite gel and its in vivo implantation. Artificial Organs 2005; 29 (10): 838-845.

13. Dickneite G, Metzner H, Pfeifer T, Kroez M, Witzke G. A comparison of fibrin sealants in relation to their in vitro and in vivo properties. Thrombosis Res 2003; 112 (1-2): 73-82.

14. Munirah S, Kim S, Ruszymah B, Khang G. The use of fibrin and poly (lactic-co-glycolic acid) hybrid scaffold for articular cartilage tissue engineering: an in vivo analysis. Eur Cell Mater 2008; 15 (41): e52.

15. Munirah S, Aminuddin B, Chua K, Samsudin O, Badrul A, Azmi B et al. Tissue-engineered human articular cartilage demonstrates intense immunopositivity for collagen type II. J Bioscience 2006; 17 (1): 9-18.

16. Ahmed TA, Dare EV, Hincke M. Fibrin: a versatile scaffold for tissue engineering applications. Tissue Engineering Part B: Rev 2008; 14 (2): 199-215.

17. Chen G, Ushida T, Tateishi T. Scaffold design for tissue engineering. Macromol Biosci 2002; 2 (2): 67-77.

18. Chen F-M, Zhang M, Wu Z-F. Toward delivery of multiple growth factors in tissue engineering. Biomaterials 2010; 31 (24): 6279-6308.

19. Pedriali CA, Fernandes AU, Santos PAd, Silva MMd, Severino D, Silva MBd. Antioxidant activity, cito-and phototoxicity of pomegranate (Punica granatum L.) seed pulp extract. Food Sci Technol 2010; 30 (4): 1017-1021.

20. Malik A, Afaq F, Sarfaraz S, Adhami VM, Syed DN, Mukhtar H. Pomegranate fruit juice for chemoprevention and chemotherapy of prostate cancer. Proc Nat Acad Sci 2005; 102 (41): 14813-14818.

21. Larrosa M, González-Sarrías A, Yáñez-Gascón MJ, Selma MV, Azorín-Ortuño M, Toti S et al. Anti-inflammatory properties of a pomegranate extract and its metabolite urolithin-A in a colitis rat model and the effect of colon inflammation on phenolic metabolism. J Nutrit Biochem 2010; 21 (8): 717-725.

22. Stowe CB. The effects of pomegranate juice consumption on blood pressure and cardiovascular health. Complementary Ther Clin Pract 2011; 17 (2): 113-115.

23. Rambhia KJ, Ma PX. Controlled drug release for tissue engineering. J ControllRel 2015; 219:119-128.

24. Engel E, Michiardi A, Navarro M, Lacroix D, Planell JA. Nanotechnology in regenerative medicine: the materials side. Trends Biotechnol 2008; 26 (1): 39-47.

25. Boisseau P, Loubaton B. Nanomedicine, nanotechnology in medicine. Comptes Rendus Phys 2011; 12 (7): 620-636.

26. Kango S, Kalia S, Celli A, Njuguna J, Habibi Y, Kumar R. Surface modification of inorganic nanoparticles for development of organic-inorganic nanocomposites - A review. Progress Polymer Sci 2013; 38 (8): $1232-1261$.

27. Vilela C, Figueiredo AR, Silvestre AJ, Freire CS. Multilayered materials based on biopolymers as drug delivery systems. Expert Opinion Drug Deliv 2017; 14 (2): 189-200.

28. Wallace SJ, Li J, Nation RL, Boyd BJ. Drug release from nanomedicines: selection of appropriate encapsulation and release methodology. Drug Deliv Translat Res 2012; 2 (4): 284-292.

29. Esfandiary E, Valiani A, Hashemibeni B, Moradi I, Narimani M. The evaluation of toxicity of carbon nanotubes on the human adiposederived-stem cells in-vitro. Adv Biomed Res 2014; 3 (1): 40.

30. Yan J, Dong L, Zhang B, Qi N. Effects of extremely low-frequency magnetic field on growth and differentiation of human mesenchymal stem cells. Electromagn Biol Med 2010; 29 (4): 165-176.

31. Pascolo L, Bortot B, Benseny-Cases N, Gianoncelli A, Tosi G, Ruozi B et al. Detection of PLGA-based nanoparticles at a single-cell level by synchrotron radiation FTIR spectromicroscopy and correlation with X-ray fluorescence microscopy. Internat J Nanomed 2014; 9:2791.

32. Brown EE, Zhang J, Laborie M-PG. Never-dried bacterial cellulose/ fibrin composites: preparation, morphology and mechanical properties. Cellulose 2011; 18 (3): 631-641.

33. Vardin H, Tay A, Ozen B, Mauer L. Authentication of pomegranate juice concentrate using FTIR spectroscopy and chemometrics. Food Chem 2008; 108 (2): 742-748.

34. Kharazi AZ, Fathi M, Bahmani F, Fanian H. Partially resorbable composite bone plate with controlled degradation rate, desired mechanical properties and bioactivity. Polymer Degrad Stabil 2011; 96 (12): 20552063.

35. Heydari P, Varshosaz J, Zargar Kharazi A, Karbasi S. Preparation and evaluation of poly glycerol sebacate/poly hydroxy butyrate coreshell electrospun nanofibers with sequentially release of ciprofloxacin and simvastatin in wound dressings. Polymers Adv Technol 2018; 29 (6): 1795-1803.

36. Ayati Najafabadi SA, Shirazaki P, Zargar Kharazi A, Varshosaz J, Tahriri M, Tayebi L. Evaluation of sustained ciprofloxacin release of biodegradable electrospun gelatin/poly (glycerol sebacate) mat membranes for wound dressing applications. Asia-Pacific J Chem Engineer 2018; 13 (6): e2255.

37. Shirazaki P, Varshosaz J, Kharazi AZ. Electrospun gelatin/poly (glycerol sebacate) membrane with controlled release of antibiotics for wound dressing. Adv Biomed Res 2017; 6 . 
$56-64$

38. Kharazi AZ, Atari M, Vatankhah E, Javanmard SH. A nanofibrous bilayered scaffold for tissue engineering of small-diameter blood vessels. Polymers Adv Technol 2018; 29 (12): 3151-3158.

39. Sridhar R, Lakshminarayanan R, Madhaiyan K, Barathi VA, Lim KHC, Ramakrishna S. Electrosprayed nanoparticles and electrospun nanofibers based on natural materials: applications in tissue regeneration, drug delivery and pharmaceuticals. Chem Soc Rev 2015; 44 (3): 790-814.

40. Zhao H, Ma L, Gao C, Shen J. A composite scaffold of PLGA microspheres/fibrin gel for cartilage tissue engineering: fabrication, physical properties, and cell responsiveness. J Biomed Materials Research Part B: 2009; 88 (1): 240-249.

41. Zhu Y, Gao C, Liu X, He T, Shen J. Immobilization of biomacromolecules onto aminolyzed poly (L-lactic acid) toward acceleration of endothelium regeneration. Tissue Engineer 2004; 10 (1-2): 53-61.

42. Lansky EP, Newman RA. Punica granatum (pomegranate) and its potential for prevention and treatment of inflammation and cancer. J Ethnopharmacol 2007; 109 (2): 177-206.

43. Munirah S, Kim S, Ruszymah BH, Khang G. The use of fibrin and poly (lactic-co-glycolic acid) hybrid scaffold for articular cartilage tissue engineering: an in vivo analysis. Eur Cell Mater 2008; 15 (41): e52.

44. Balakrishnan B, Banerjee R. Biopolymer-based hydrogels for cartilage tissue engineering. Chem Rev 2011; 111 (8): 4453-4474.

45. Gentile P, Chiono V, Carmagnola I, Hatton PV. An overview of poly (lactic-co-glycolic) acid (PLGA)-based biomaterials for bone tissue engineering. Internat J Mol Sci 2014; 15 (3): 3640-3659.
46. Amass W, Amass A, Tighe B. A review of biodegradable polymers: uses, current developments in the synthesis and characterization of biodegradable polyesters, blends of biodegradable polymers and recent advances in biodegradation studies. Polymer Internat 1998; 47 (2): 89-144.

47. Mano J, Silva G, Azevedo HS, Malafaya P, Sousa R, Silva SS et al. Natural origin biodegradable systems in tissue engineering and regenerative medicine: present status and some moving trends. J Royal Soc Interface 2007; 4 (17): 999-1030.

48. Shi J, Votruba AR, Farokhzad OC, Langer R. Nanotechnology in drug delivery and tissue engineering: from discovery to applications. Nano Lett 2010; 10 (9): 3223-3230.

49. Nikalje AP. Nanotechnology and its applications in medicine. Med Chem 2015; 5 (2): 081-9.

50. Bhattarai N, Ramay HR, Chou S-H, Zhang M. Chitosan and lactic acid-grafted chitosan nanoparticles as carriers for prolonged drug delivery. Internat J Nanomed 2006; 1 (2): 181

51. Souza TG, Ciminelli VS, Mohallem NDS, editors. A comparison of TEM and DLS methods to characterize size distribution of ceramic nanoparticles. J Physics: Conference Series; 2016: IOP Publishing.

52. Kim HJ, Im GI. Chondrogenic differentiation of adipose tissue-derived mesenchymal stem cells: Greater doses of growth factor are necessary. J Orthop Res 2009; 27 (5): 612-619.

53. Praveen G, Sreerekha P, Menon D, Nair SV, Chennazhi KP. Fibrin nanoconstructs: a novel processing method and their use as controlled delivery agents. Nanotechnology 2012; 23 (9): 095102. 